\title{
СРАВНИТЕЛЬНАЯ ХАРАКТЕРИСТИКА КЛИНИКО-ПАТОГЕНЕТИЧЕСКИХ ОСОБЕННОСТЕЙ ПЕРВОГО И ПОВТОРНОГО ИНСУЛЬТОВ
}

\section{Б.Г.Гафуров}

доктор мед наук, профессор, заведующий кафедрой неврологии Ташкентского института усовершенствования врачей, главный невролог МЗ Республики Узбекистан

\begin{abstract}
На материале клинического и лабораторно-инструментального исследования 81 случая повторного (в 63 случаях после первого ишемического и в 18 случаях после первого геморрагического) инсульта изучены клиникопатогенетические соотношения между первым и повторным инсультами. Выявлена тенденция к локализации очага повторного инсульта в том же полушарии в случае неизменности его клинической формы по сравнению с первым инсультом и локализации очага в другом полушарии при изменении клинической формы (ишемический на геморрагический и наоборот). Среди патогенетических типов ишемического инсульта наиболее стабильными при повторном инсульте (по сравнению с первым инсультом) оказались лакунарный и гемореологический типы, при остальных вариантах патогенез повторного инсульта менялся чаще. Сделан вывод, что дальнейшие исследования в этом направлении помогут в решении вопросов прогнозирования повторных инсультов и улучшения результатов вторичной профилактики.

Ключевые слова: повторный инсульт, полушарная латерализация, патогенетический тип.
\end{abstract}

$\mathbf{K}$ линический опыт показывает, что не всегда патогенетический тип первого инсульта совпадает с патогенетическими типами повторного ишемического инсульта. Однако на достаточно большом клиническом материале, эти вопросы плохо изучены. Кроме того представляет интерес вопрос о сосудистом бассейне а также полушарной латерализации первого и повторного ишемических инсультов, а так же возможность клинической трансформации ишемического и геморрагического первого и повторного мозговых инсультов.

Нами проведено проспективное и ретроспективное исследование 81 случая повторного мозгового инсульта (63 больных с первым ишемическим и 18 с первым геморрагическим инсультами) с детальной клинико-патогенетической оценкой каждого случая. При этом на основании вышеуказанных критериев были проанализированы патогенетические типы первого и повторного инсультов при ишемическом его варианте. Верификация патогенетических типов ишемического инсульта проводилась клинически и с использованием обширного арсенала инстументально-лабораторных методов исследования (КТ, ангиография, ультразвуковая доплерография мозговых сосудов, ЭКГ и ЭХО-КГ, коагулологические исследования крови и др.).

В результате проведённого исследования выявлено, что между больными с повторным ишемическим инсультом (ПИИ) и повторным геморрагическим инсультом (ПГИ) имеется ряд существенных различий. В частности установлено, что средний возраст больных, перенесших ПИИ, достоверно выше по сравнению с пациентами, перенесшими ПГИ. Средние сроки после первого инсульта, при ПИИ достоверно короче по сравнению с группой с ПГИ. Интересно отметить, что повторный и ишемический и геморрагический инсульты развиваются на фоне разных уровней среднего артериального давления (САД). В частности ПИИ достоверно чаще развивается на фоне САД ниже 120 мм рт. ст., тогда как ПГИ достоверно чаще развивается на фоне САД выше 120 мм рт. ст. Больничная летальность при ПГИ достоверно выше, чем при ПИИ.

Интересные данные были получены нами при исследовании вопросов о клинической трансформации ПИИ и ПГИ по сравнению с первым. Так при геморрагических инсультах (ГИ) по сравнению с ишемическими (ИИ) повторные инсульты относительно реже развиваются по тому же геморрагическому типу (72,2\% случаев), тогда как при ишемическом инсульте повторный инсульт сравнительно чаще также бывает ишемическим (в 87,3\% случаев). Это означает, что факторы риска развития ИИ более стабильны, чем аналогич-

e-mail: cool.bahtiyar@yandex.com 
ные при ГИ. Интересно отметить, что у всех 5 больных, у которых после ранее перенесенного ГИ развился ПИИ, последний по своим клинико-патогенетическим и нейровизуализационным характеристикам был лакунарным. Представляет интерес также тот факт, что у 8 больных, перенесших ПГИ после ИИ, очаг геморрагии имел локализацию в другом полушарии.

Интересные данные были получены нами при анализе клинической трансформации первого и повторного ИИ и ГИ с учетом полушарной латерализации патологического процесса. Выявлено, что правополушарный ГИ в 57\% случаях трансформировался в аналогичный повторный правополушарный ПГИ и в 43\% случаях трансформировался в повторный левополушарный ПИИ. Левополушарный ГИ в 80\% случаях трансформировался в аналогичный левополушарный ПГИ и в 20\% случаях трансформировался в левополушарный ПИИ. Правополушарный ИИ в 78\% случаях трансформировался в правополушарный ПИИ и в $22 \%$ случаях в левополушарный ПГИ. Более полиморфной оказалась трансформация левополушарного ИИ. В 78\% случаях он трансформировался в левополушарный ПИИ. В остальных случаях наблюдалась разнообразная по клинической форме и латерализации процесса трансформация (правополушарный ПГИ, правополушарных ПИИ и инсульт в ВББ). Достаточно стабильной оказалась трансформация редкого варианта ГИ в ВББ. Нами наблюдался всего 1 такой случай. Это было небольшое кро-воизлияние в варолиев мост и при ПГИ той же локализации больной скончался. И наконец, ИИ в ВББ в большинстве случаях - 75\% случаях трансформировался в ПИИ в ВББ и в 25\% случаях в ПГИ в каротидном бассейне правого полушарии. Таким образом, результаты данной части исследования свидетельствуют о том, что в целом, в большинстве случаев, повторный инсульт развивается в том же полушарии. Однако имеются некоторые особенности клинической трансформации разновидности инсультов. В частности при повторном инсульте можно отметить тенденцию к лате- рализации процесса в противоположном полушарии по отношению к первичному очагу в случае трансформации ГИ в ПИИ.

Достаточно интересные результаты получены нами при анализе клинической трансформации при ПИИ с учетом патогенетического типа первого инсульта. Установлено, что наиболее стабильным в отношении клинической трансформации повторного инсульта оказался лакунарный инсульт (ЛИ). В $100 \%$ случаях повторный инсульт оказался также ЛИ. То же самое можно сказать в отношении варианта гемореологического варианта (ГР). Повтор-ный инсульт при первом ГР варианте так же оказался $100 \%$ случаях ГР. Вместе с тем, полиморфизм клинической трансформации повторного инсульта по отношению к первому выявлялся при атеротромбтическом (АТР), кардиоэмболическом (КЭ) и гемодинамическом (ГД) вариантах ИИ. В частности наиболее полиморфным оказался в этом отношении ГД вариант ишемического инсульта. Лишь в 2 случаях из 8 он так же был ГД при повторном инсульте. Интересно, то что, в 50\% случаев ГД вариант трансформировался в КЭ вариант, что обусловлено, на наш взгляд, тем, что в патогенезе ГД варианта ИИ чаще всего играет роль сердечная недостаточность, которая обусловлена ишемической болезнью сердца и в большинстве случаев постинфарктным процессом с вероятной организацией пристеночного тромба в сердце. В небольшом проценте случаев ГД вариант инсульта трансформировался в гемореологический (ГМР) и ЛИ варианты. На втором месте по частоте по полиморфизму патогенетических типов повторного инсульта стоит АТР вариант. Лишь в 7 случаях из 11 АТР ИИ оставался АТР вариантом и поровну при повторных случаях он трансформировался в ГД и ЛИ варианты. Относительно стабильными оказались характеристики КЭ инсульта, в частности лишь в одном случае из 8 КЭ вариант при повтором инсульте трансформировался в ГМР, а в остальных случаях ПИИ носил тот же патогенетический вариант.

Таким образом, данная часть нашего ис- 
следования свидетельствует о том, что патогенетические механизмы, реализующие первичный и повторный мозговые инсульты, могут со временем трансформироваться. В частности, трансформация наиболее значима при таких вариантах ИИ, как АТР и ГД, что следует учитывать при проведении мероприятий по вторичной профилактике инсультов.

В заключение следует отметить, что результаты нашего исследования, позволяют уточнить некоторые клинические и этиопатогенетические аспекты повторных инсультов. В частности представляют интерес данные о том, что ПИИ развивается после первого ИИ быстрее, чем ПГИ после первого ГИ. Существуют споры относительно уровня АД и риска повторного инсульта. По нашим данным риск ПИИ выше при более низких цифрах АД, а риск ПГИ выше при более высоких цифрах. Представляет интерес выявленная тенденция, говорящая о том, что в случае ПИИ после первого ГИ и наоборот очаг повторного инсульта локализуется чаще в другом полушарии, а при отсутствии клинической трансформации инсульта (то есть ГИ - ПГИ и ИИ - ПИИ) очаг чаще имеет ту же полушарную латерализацию. Существует мнение о том, что ПИИ должен иметь тот же патогенетический тип, что и первый. Наше исследование показало, что такая точка зрения справедлива по отношению к ЛИ и ГМР типам. Что касается других типов ИИ, то, по нашим данным, повторный инсульт может "менять" свой патогенез. В этом отношении наименее стабильными оказались ГД и АТР типы ИИ. Можно быть уверенным, что дальнейшие исследования в этом направлении с детальным анализом факторов риска первого и повторного инсультов помогут в решении вопросов прогнозирования повторных инсультов и улучшении результатов вторичной профилактики.

\title{
SUMMARY
}

\section{COMPARATIVE CHARACTERISTIC OF CLINICAL-PATHOGENETIC PECULIARITIES OF THE FIRST AND REPEATED STROKES}

\author{
B.G.Gafurov \\ Doctor of Medicine, Professor, Head of the Department of Neurology \\ of the Tashkent Institute for Advanced Training of Doctors, \\ Senior neurologist of the Health Ministry of Uzbekistan
}

Based on the data of clinical and laboratory-instrumental study of 81 patients with secondary stroke, including 63 cases after the first ischemic stroke and 18 cases after the first hemorrhagic stroke, we compared clinical-pathogenetic correlations between first and second strokes. A trend towards the localization of a focus of secondary stroke in the same hemisphere in case of the similar to the first stroke clinical form and in the other hemisphere in case of changing the clinical form (ischemic to hemorrhagic and vice versa) was found. Among the pathogenetic types of ischemic stroke, lacunar and hemoreologic types were most stable in the secondary stroke com-pared to the first one. In other variants, the pathogenesis of secondary stroke changed more often. The authors concluded that further research in this direction would help to solve issues in prediction of secondary stroke and improvement of secondary prophylaxis.

Key words: secondary stroke, pathogenetic types of stroke, secondary prophylaxis. 


\title{
XÜLASə
}

\section{ILKIN Və TOKRAR INSULTLARIN KLINIK-PATOGENETIK XÜSUSIYYYOTLORININ MÜQAYISOLI XARAKTERISTIKASI}

\author{
B.Q.Qafurov \\ Tibb elmlar doktoru, professor, Daşkənd həkimlari təkmillaşdirmə institutunun \\ nevrologiya kafedrasının müdiri
}

Kliniki və laborator-instrumental müayinələrə əsaslanaraq 81 təkrar insult hadisələrində (63-ü ilkin işemik insultdan sonra və 18-i ilkin hemorragik insultdan sonra), ilkin və təkrar insultlar arasında kliniki-patogenetik nisbəti öyrənilib. Aydın olmuşdur ki, kliniki formasını dəyişmiş insultlarda (işemikdən hemorragikə və ya tərsinə) ocağın yerləşməsi digər yarımkürədə olur, hal bu ki, kliniki formasını dəyişməyən təkrarı insultun ocağı həmin yarımkürədə yerlə̧̧məsinin meyilliyi aşkarlanır. İşemik insultun patogenetik tiplərinin təkrar insult zamanı ən stabilləri lakunar və hemoreoloji olanlardır. Digər variantlarda təkrar insultların patogenezi daha tez dəyişirdi. Belə bir nəticə çıxarıldı ki, bu istiqamətdə aparılan tədqiqatlar təkrar insultların proqnozlaşdırılmasında və ikincili profilaktik nəticələrin yaxşılaşmasında böyük köməklik göstəcək.

Acar sözlər: təkrar insult, yarımkürə lateralizasiyası, patogenetik tip. 